\title{
EL LUGAR DE LA IMPOSTURA EN EL AUTOENGAÑO: SOBRE EL ARQUITECTO DE HITLER
}

\author{
Ángela Uribe Botero* \\ doi:10.11144/Javeriana.uph31-63.iaah
}

\begin{abstract}
RESUMEN
En este texto hago referencia a un conjunto de afirmaciones que, una vez finalizada la Segunda Guerra Mundial, hizo sobre su situación en el Tercer Reich Albert Speer, el arquitecto de Hitler. El núcleo de esta serie de afirmaciones es el término "autoengaño". Valiéndome de las palabras de Speer, quisiera destacar un rasgo que, a mi modo de ver, acompaña el proceso del autoengaño: la impostura. Hago con ello énfasis en que el autoengaño tiene lugar, con frecuencia, en un contexto del que participan los demás. Intento mostrar de qué modo, la manera como la presencia de los otros puede constituirse en audiencia para el autoengañado ofrece las condiciones para que el autoengaño sea más o menos notorio, más o menos fácil.
\end{abstract}

Palabras clave: Hitler; Albert Speer; autoengaño; impostura; audiencia

\footnotetext{
${ }^{*}$ Universidad Nacional de Colombia, Bogotá, Colombia.

RECIBIDO: 20.04.14

ACEPTADO: 25.05.14

DISPONIBLE EN LÍNEA: 02.12 .14

Para citar este artículo: Uribe Botero, A. (2014). El lugar de la impostura en el autoengaño: sobre el arquitecto de Hitler. Universitas Philosophica, 31(63), pp. 167-180, ISSN 01205323, ISSN en línea 2346-2426, doi: 10.11144/Javeriana.uph31-63.iaah
} 


\title{
THE PLACE OF IMPOSTURE IN SELF- DECEPTION: ON HITLER'S ARCHITECT
}

\author{
Ángela Uribe Botero
}

\begin{abstract}
In this article I make references to a set of statements made by Albert Speer-Hitler's architect-, about his situation in the Third Reich after the end of the Second World War. The heart of these statements is the term "self-deception". Taking into account of Speer's words, I emphasize on a feature which, as I see it, goes along with the process of self-deception: imposture. With the inclusion of imposture in the discussion on self-deception, I emphasize on the fact that it frequently takes place in a context made not only by the self-deceiver alone, but by others as well. In this sense, the presence of the others or what I want to call "the audience" is a significant part of what makes self-deception more or less notorious, more or less easy to occur.
\end{abstract}

Key words: Hitler; Albert Speer; self-deception; imposture; audience 
The total insensibility of mind with respect to those horrid crimes, after the commission of them, manifestly shows that he did some way or other delude himself.

Joseph Butler

\section{El arquitecto de Hitler}

Entre el 20 DE NOVIEMBRE DE 1945 y el 1 de octubre de 1946 tuvo lugar en la devastada Alemania de la posguerra el famoso Proceso Internacional de Núremberg. Por primera vez en la historia comparecían ante un tribunal internacional algunos de los agentes de algo que fue dado a conocer como "crímenes sin precedentes". La característica compartida entre los veinticuatro acusados en este proceso era el hecho de que todos y cada uno de ellos había formado parte de la cúpula del Tercer Reich. El carácter "sin precedentes" de los crímenes que se les imputó respondió a las dificultades que tuvo que enfrentar el Tribunal Internacional de Núremberg para convenir en torno a una serie de nuevas categorías jurídicas. A marchas forzadas y, sin embargo, con el rigor que imponía el contexto, los jueces determinaron cuatro categorías de crímenes que, se suponía, transmitirían al mundo una idea vaga de lo que hizo posible el Tercer Reich. A los acusados les fueron imputados cargos por crímenes de guerra, crímenes contra la humanidad, genocidio y crímenes tipificados como "guerra de agresión". Las características de la justicia que quiso imponer el Tribunal Internacional en Núremberg exigían que una vez que fuese descrito el tipo de delito y antes de la exhibición de las pruebas, los acusados fueran conminados a responder a la siguiente pregunta: “¿Se considera usted culpable de los crímenes de los que se le acusa?" Todos y cada uno de los veinticuatro acusados, uno por uno, respondió a esta pregunta con un rotundo: "soy inocente".

Quisiera en este texto hacer referencia a un conjunto de afirmaciones que hizo sobre su situación en el Tercer Reich uno de estos acusados: Albert Speer, el arquitecto de Hitler. Este conjunto de afirmaciones aparece en el libro Memorias, escrito por él durante el tiempo en que estuvo preso en la cárcel de Spandau y a partir del momento en el que el Tribunal Internacional de Núremberg dictó la sentencia que lo condenó a vivir 20 años en prisión. Con las afirmaciones contenidas en su libro, apelaba Speer a la posibilidad de ofrecer una explicación sobre su decisión de convertirse en uno de los hombres más importantes de Hitler; es decir, sobre su decisión de ser el arquitecto del Führer y, más tarde, a partir de 1942, su Ministro de 
Armamentos. El núcleo de esta explicación, que quiero llamar "psicológica", es el término "autoengaño".

La discusión filosófica actual sobre las características precisas que sirven para describir las diversas formas como tiene lugar el autoengaño es bastante amplia. No entro en detalles sobre esta discusión. Las referencias que incluyo en este trabajo a algunos de los autores que participan de ella servirán solamente para llamar la atención acerca de las notables semejanzas entre la forma como Speer describe su condición de autoengañado y algunas de las características generales del proceso psicológico que, según estos autores, son constitutivas del autoengaño (Mele, Martin, Johnston, Baron, Audi). Valiéndome de las palabras de Speer, quisiera, por otra parte, destacar un rasgo que, a mi modo de ver, acompaña dicho proceso: la impostura. Antes de desarrollar el argumento que desearía defender en este trabajo es preciso hacer una aclaración: en las descripciones que hacen los autores a quienes menciono sobre los casos paradigmáticos de autoengaño no se contempla explícitamente la presencia de la impostura. Quizás se deba a que esta, como se verá, no remite directamente al proceso psicológico que define al autoengaño y que es, para los autores que menciono, el centro la discusión sobre el tema.

\section{La dimensión psicológica del autoengaño}

HaCia finales de 1931 Albert Speer se hizo miembro del partido Nacional Socialista alemán. Tres años después de esto era el arquitecto del Reich. Luego de tres años más, y hasta el 8 de mayo de 1945, fue su Ministro de Armamentos y uno de los hombres más cercanos a Hitler. Varios años después de finalizada la guerra, la voz de Speer pasó a ser una de las más escuchadas por quienes quisieron saber por qué él, pues a diferencia de los demás acusados en el Tribunal Internacional de Núremberg, se había mostrado dispuesto asumir el costo de su cercanía con Hitler.

Antes de la guerra pero también durante ella, Speer no fue más que uno de los tantos alemanes comunes y corrientes que no atendió con clara convicción a los llamados estridentes de la ideología nazi. A pesar del tono beligerante y evidentemente antisemita que ya durante esos años dejaba oír la histeria nazi, Speer no se veía como antisemita; él, ante todo, era arquitecto (Speer, 2001, p. 43). Tal como se describe a sí mismo, Speer era tan exclusivamente arquitecto que el odio explícito hacia los judíos por parte 
de Hitler y de los demás miembros del partido no lo conmovió. ¿Qué le hacía pensar a él que el antisemitismo explícito recurrentemente en los discursos de los dirigentes del partido, en las Leyes de Núremberg y en los pogromos del 38 no era asunto suyo? En las primeras páginas de sus Memorias Speer hace tímidos esfuerzos por responder a esta pregunta. Dice él:

Mis ganas de trabajar me permitieron no pensar en cuestiones que debía haberme planteado. En la prisa diaria se ahogaba más de una duda. Mientras escribía estas memorias, mi creciente sorpresa llegó a la consternación cuando comprobé que hasta 1944 raramente, por no decir nunca, había encontrado tiempo para reflexionar sobre mí mismo y mis actividades y para considerar el sentido de mi propia existencia. Hoy, al rememorar todo aquello, tengo a veces la impresión de que en aquella época algo me levantó del suelo, me separó de mis raíces y me sometió a toda clase de fuerzas extrañas a mí. (Speer, 2001, p. 60)

Más adelante en el libro, y con el propósito de averiguar por su propia cuenta qué fue, en últimas, ese "algo" que "lo levantó del suelo" y lo sometió a "toda clase de fuerzas extrañas", Speer hace unas cuantas referencias a algo más difícil de transferir a otra instancia de la agencia que no fuera él mismo: el autoengaño. El término, aplicado a sí mismo, aparece tres veces en el libro ${ }^{1}$. Una de ellas llama especialmente la atención:

Al igual que en una sala de espejos cada autoengaño se multiplicaba en la imagen confirmada una y otra vez, de un modo quimérico, que no tenía nada que ver con la realidad exterior. En estos espejos sólo podía ver reflejada repetidamente mi propia imagen; ninguna mirada extraña perturbaba la uniformidad de cien rostros siempre iguales y que siempre eran el mío. (Speer, 2001, p. 529)

Los esfuerzos de Speer por darle un sentido a la metáfora de los espejos no son explícitos y tampoco están articulados sistemática y directamente al uso que él hace del término "autoengaño" para referirse a sí mismo. En lo que sigue intento articular las dos cosas; es decir, la metáfora de los espejos, junto con el uso que Speer hace del término "autoengaño".

El autoengaño es concebido por gran parte de los autores que se ocupan hoy del tema como un proceso a través del cual un agente llega a creer $\neg p$,

${ }^{1}$ Las otras dos se encuentran en las páginas 116 y 741 del mismo libro. 
(ej., $p$ ) a pesar de que todas la evidencias con las que cuenta hacen pensar que el agente no podría creer otra cosa más que $p($ ej., $\neg p)$. El sentido del término así propuesto presupone una condición: solo es posible estar autoengañado en la forma de creer que algo no es el caso bajo la condición de que, desde el punto de vista de un tercero, el agente cuente con evidencia suficiente para creer que, en efecto, ese algo sí es el caso. Dadas ciertas condiciones que son psicológicas, se afirma, el agente evade esa evidencia hasta terminar por creer que ella no contradice lo que él cree (Martin, Rorty, Jonhston, Baron, Mele $)^{2}$. Desde el punto de vista de un espectador atento, el agente, repito, no podría más que creer que ese algo sí es el caso. Por ejemplo, a los ojos de un espectador atento, Speer contaba con evidencia suficiente (documentos, discursos, recuerdos de conversaciones) para creer que el régimen del que él formaba una parte muy activa llevaba a cabo ejecuciones forzosas contra ciertos grupos de personas y, sin embargo, él no creía que esto último fuera así (pues insistía en no atender a la evidencia que soportaba el hecho de que lo fuera).

La respuesta de algunos autores a la pregunta acerca de por qué un agente no cree que sea verdad aquello que para un espectador atento es evidente, remite a una primera instancia en el proceso psicológico al que aluden ellos: la motivación. En términos generales, la motivación hace referencia a los contenidos de las creencias, dado que un agente ha preferido adoptarlas en determinadas circunstancias (Mele, 2009, pp. 261-263; Martin, 1986, p. 13). Una segunda instancia de la indagación por el proceso sicológico en que consiste el autoengaño, añadiría yo, debería responder a la pregunta acerca de por qué está motivado un agente a creer aquello que es contrario a las evidencias con las que -desde el punto de vista de un espectador atentodicho agente debería contar. Mi respuesta, muy general, a esta pregunta es la siguiente: la motivación para que un agente insista en creer que $\neg p$, a pesar de que las evidencias con las que debería contar lo conducirían a creer que $p$, remite, a su vez, a las inclinaciones del agente; es decir, a los deseos que tiene él de obtener algo que, de uno u otro modo, favorece sus intereses o, puesto en otros términos, al temor que tiene de que estos no sean satisfechos. En

\footnotetext{
${ }^{2}$ Quien, a mi manera de ver, ha ofrecido la definición más clara del autoengaño, entendido de este modo es Alfred Mele (2001, p. 10): "Postulamos autoengaño en casos particulares para explicar datos: por ejemplo, el hecho de que hay excelentes razones para asumir que $S$ cree que $p$, a pesar de que lo que realmente ocurre es que las evidencias que tiene $S$ lo hacen creer que $\neg p "$.
} 
efecto, si hay un riesgo de que algo no sea el caso a causa de la admisión de cierta evidencia, entonces, dicho agente incurre en un proceso de negación de esa evidencia (Martin, 1986, pp. 11-13; Mele, 2001, pp. 24/43-60; Rorty, 1988, p. 18). Vista de este modo, la evidencia constituye para el agente una interferencia en el camino hacia aquello a lo que está inclinado. En otras palabras, afirmar la verdad de la evidencia es, desde el punto de vista del agente, una forma de actuar contra sus intereses.

En la discusión sobre el tema hay diversas maneras de describir el anterior proceso. No me extiendo en ellas porque, bien vistas, todas tienen en común los rasgos generales (que son los que tienen importancia en el contexto al que me refiero) de una explicación psicológica del "autoengaño". En primer lugar, se admite que quien se engaña a sí mismo se niega a ver algo que para un espectador atento es evidente que existe, y se añade: el autoengañado evade verlo y a fuerza de evadirlo termina por reinterpretar la evidencia a su favor. El hecho de reinterpretar la evidencia a su favor suele conducir al autoengañado hasta la situación de negar su lugar en lo que ocurre, como quien afirma: "quizás sucede algo allá, y sin embargo, cualquier cosa que suceda, no me afecta, no tiene nada que ver conmigo, yo no la provoqué". Es decir, aquello que desde la perspectiva de un observador atento es un hecho cierto, desde la del autoengañado, no solo es dudoso, sino que tampoco es un hecho. Desde el punto de vista de un espectador atento la participación de Speer en lo sucedido durante el régimen nazi no puede ser más que un hecho cierto; mientras que para Speer, esto mismo fue fácilmente ahogado por la "prisa diaria" con la que se desempeñaba como arquitecto y ministro del Reich (Speer, 2001, p. 60). El autoengañado, entonces, termina por privilegiar la creencia según la cual aquello que está ahí no solo no es percibido por él (Audi, Martin, Mele, Rorty, Baron), sino que, justamente por esto mismo, no existe. En segundo lugar, el autoengañado tiene intereses (inconscientes, ocultos, no intencionales) que lo conducen de evadir ver hasta negar la existencia de aquello que para otros es evidentemente el caso. Paso a ilustrar el proceso valiéndome de las palabras de Speer.

Algunas de las páginas de las Memorias contienen descripciones claras de la forma como proceden en Speer tanto la evasión como la negación. A pesar de la monumentalidad carga de propaganda calculada y explícita en las construcciones que Hitler dejaba a su cargo podía vivir, como muchos otros miembros del partido, con la idea de que "la política era demasiado complicada" (Speer, 2001, p. 61). Y dado que tenía muchos deseos de 
trabajar (Speer, 2001, p. 60), a fuerza de moverse ávidamente nada más que en el trozo de mundo constituido por el trabajo que le correspondía, podía restarle importancia al contenido moral que tenía su lugar en el Reich (Speer, 2001, pp. 125-187). Mientras tanto no veía las consignas antisemitas que aparecían en los cientos de pancartas colgadas en los edificios que él mismo ordenaba derribar; no oía los discursos y, en las tantas veces que tomó té en la casa de campo de Hitler, no participó de las conversaciones sobre "la solución final al problema con los judíos". Mientras, algunos años después, sirvió al Reich como Ministro de Armamentos y "ciego" por su interés en cumplir con su misión, Speer parece no haber visto que, en un solo año, casi veinticinco mil de los trabajadores de las fábricas que él mismo controlaba murieron en condiciones comparables a las que se vivían en los campos de concentración (Kershaw, 2007, p. 689). El mismo entusiasmo con el que asumía su responsabilidad como arquitecto parece haber impedido también que, años más tarde, viera cómo sus armas "milagrosas" servían para destruir ciudades enteras en la guerra del occidente (Kershaw, 2007, p. 814).

Refiriéndose a uno de estos eventos ${ }^{3}$ dice Speer lo siguiente: “¿Percibí entonces, siquiera por un momento fugaz, que estaba comenzando algo que habría de concluir con la destrucción de un grupo de nuestro pueblo y que también cambiaría mi sustancia moral? No lo sé, me tomé más bien con indiferencia lo sucedido" (Speer, 2001, p. 210). Sobre su decisión de servir al Reich a partir de 1942 como Ministro de Armamentos añade: "Obsesionado con mi misión no aspiraba a que disminuyeran mis competencias, sino al contrario. El aprecio de Hitler, el sentido del deber, el orgullo, la autoestima...: todo se juntaba. Al fin y al cabo era, con mis 36 años de edad, el ministro más joven del Reich" (Speer, 2001, p. 382).

Si se atiende a los rasgos del fenómeno psicológico que he tenido en cuenta hasta acá, cada una de estas citas constituye una descripción en primera persona del proceso conocido como "autoengaño". 1) Speer tenía muchas ganas de trabajar. Además, los resultados de su trabajo debían incluir fama y poder. 2) Afirmar su deseo de cumplir con su trabajo lo obligaba a evadir ver lo que, a los ojos de un espectador atento, evidentemente sucedía en Alemania: el propósito de expansión de Hitler, los pogromos, el Holocausto,

\footnotetext{
${ }^{3}$ Speer se refiere con esto a la Noche de los Cristales, que tuvo lugar en Munich, durante la noche del 9 de noviembre de 1938.
} 
la guerra de aniquilación y la esclavitud. La evasión condujo finalmente en Speer a negar que ocurriera eso que ocurría; más precisamente, lo condujo a negar su lugar protagónico en lo que causó aquello que ocurría. En palabras del propio Speer: “¿Qué más me daba todo aquello?” (Speer, 2001, p. 204), "me tomé más bien con indiferencia lo sucedido" (Speer, 2001, p. 210). Posiblemente esto explique la declaración de inocencia que hizo él en el Juicio Internacional de Núremberg.

En términos de la discusión filosófica sobre el autoengaño, la incapacidad de Speer para percibir, año tras año, su lugar protagónico en el desastre se explica, entonces, de la siguiente manera: su actitud evasiva en relación con aquello que él mismo provocaba lo condujo a adoptar una creencia que, desde la perspectiva de un observador atento, era evidentemente falsa. Desde este punto de vista, lo que sucedió durante el régimen nazi, no solamente ocurrió mientras Speer trabajaba para Hitler sino que fue, de hecho y en gran medida, provocado por el propio Speer. La motivación para adoptar la falsa creencia es justamente lo que explica el modo como trató Speer la evidencia. Con ella competían claramente sus intereses: su obsesión con el trabajo, el aprecio de Hitler, su sentido del deber, su orgullo y su autoestima (Mele, 2001).

\section{La impostura y la audiencia}

En sus MEMORIAS, SPEER ALUDE A UN RASGo de su condición de autoengañado que quiero destacar. Dice él (2001, p. 62): “cuando oía cómo los judíos, francoalemanes, socialdemócratas o testigos de Jehová eran considerados presas de caza por los que me rodeaban, actuaba como si todo aquello no tuviera nada que ver conmigo"4.

Propongo hacer énfasis en que la afirmación de Speer acerca de su disposición para la evasión incluye la descripción de sí mismo como una suerte de impostor. Lo dicho arriba sobre los rasgos generales del autoengaño no contempla la circunstancia de que este se exprese en una suerte de impostura. Esto se debe a que dicha descripción responde solamente por los rasgos, si se quiere, internos, es decir, psicológicos, del autoengaño. Sin embargo, el uso de los términos "actuaba como si", incluidos en la descripción que Speer

\footnotetext{
${ }^{4}$ El énfasis es mío.
} 
hace de sí mismo, tiene dos implicaciones. A mi manera de ver estas dos implicaciones podrían llegar a ser propias de casos prototípicos de autoengaño $\mathrm{y}$, en esa medida, acompañarían la forma como un autoengañado evade y niega la evidencia que le concierne. En primer lugar, quien "actúa como sí", evidentemente actúa; es decir, aparece ante los otros. Difícilmente se actúa en ausencia de ellos. Quien actúa, entonces, tiene ante sí a los otros, aún cuando sea solamente en la forma de imaginarlos. En segundo lugar, quien actúa "como sí" asume una pose. Es decir, aparece ante los otros de un modo que no es consistente con la evidencia que está ahí reclamando su atención. Qué tan costosa y qué tan notoria le resulte su pose al autoengañado, depende nada más que de las características de la audiencia; es decir, de la disposición que muestran los otros para servir también como impostores o, en su defecto, como agentes críticos en relación con la ceguera del autoengañado. Con lo anterior solo quiero destacar el hecho de que la descripción del proceso a través del cual una persona se engaña a sí misma podría enriquecerse si se atiende al lugar que ocupan los otros en ese proceso.

Si lo que afirmo es defendible, entonces, la "ceguera" de Speer se manifestaba de cierta forma, por la que el autoengaño evoca una puesta en escena. En el caso de Speer, la puesta en escena respondía nada más y nada menos que a su pequeño parlamento en el inmenso teatro del Tercer Reich. En ese inmenso teatro es, justamente, en lo que hacen pensar las historias que se cuentan sobre la Alemania de Hitler. En la medida en que la Alemania nazi pudiera ser descrita de este modo, entonces, no solo Speer, sino muchos millones de alemanes desempeñaban, también, sus correspondientes papeles, y lo hacían en la medida en que se los exigían sus respectivos parlamentos. Por muy diversas razones y aun teniendo en cuenta las distintas maneras como millones de alemanes hicieron parte -directa o indirectamente- del régimen nazi -porque lo avalaron, se beneficiaron silenciosamente de él, o fueron sus agentes directos-, como lo veo, a todos ellos es común, no solo la evasión, sino también, incluso, hasta la negación. Dadas las dimensiones de lo que ocurría en todos ellos, parece haberse cumplido el proceso que he descrito acá y que conduce al autoengaño. Durante el periodo de la Alemania de Hitler bien pudo haber ocurrido, y por diversas razones que apuntan todas a intereses privados, que ninguno de muchos millones de alemanes vio lo que, desde la perspectiva de un espectador atento, era evidentemente una serie de hechos: su participación ya sea activa o pasiva, lejana o cercana en los pogromos, en las detenciones forzosas, en las desapariciones, en los campos de concentración y de exterminio, en las condiciones esclavizantes de trabajo, etc. 
Lo anterior se aclara mejor si se recuerda en qué medida vivían esos millones de alemanes bajo evidentes condiciones de aislamiento ${ }^{5}$. En estas condiciones unos y otros no estuvieron presentes para hablar con los demás sobre lo que sucedía; unos y otros, por diversas razones y protegidos, ya fuera entre los muros de sus casas o sirviendo de eslabones en el aparataje burocrático, no estaban ahí para dar, en los términos adecuados, testimonio de lo que evidentemente estaba sucediendo; no estaban ahí para reconocer su lugar en ello. Son estas condiciones las que hacen pensar que pocos, entre la audiencia para la cual Speer actuaba "como sín", estaban realmente atentos a la evidencia, esto es, a "la realidad exterior". Sobre esto dice el propio Speer (2001, p. 529): "ninguna mirada extraña perturbaba la uniformidad de cien rostros siempre iguales y que siempre eran el mío". De haber estado atentos a la evidencia, de no haber estado aislados, esos millones de alemanes tendrían que haberse comunicado entre ellos sobre lo que ocurría. De haberse comunicado entre ellos sobre lo que ocurría, esos millones de alemanes no habrían podido más que atender a la evidencia en la forma de referirse a ella como una realidad que les concernía. Allí donde la evidencia sobre lo que ocurre es evadida para más adelante negar el lugar que uno ocupa en lo que sucede, es poco, si no nada, lo que queda para la comunicación entre las gentes. Difícilmente se comunican entre sí quienes, enredados entre espejos que proyectan solamente sus propias imágenes y ayudados por la propaganda manipuladora, no ven lo que hay para ver. Todo esto se debe a que difícilmente se comunican las personas entre sí más que sobre la base de lo que ocurre y que está ahí llamando su atención. Al parecer, pues, no solo Speer vivía "de un modo quimérico" contemplando la imagen distorsionada que una serie de espejos proyectaba sobre sí mismo.

En lo que sigue, quisiera fortalecer la idea de la relación entre la audiencia y la impostura en el autoengaño. Hago esto aludiendo a dos afirmaciones a través de las cuales Hannah Arendt describe el proceso que da lugar al autoengaño. En la primera de ellas dice: "Un centinela encargado de vigilar y advertir a una población de la aproximación del enemigo, lanzó por broma una falsa alarma y fue después el último en correr a las murallas para defender la ciudad de los enemigos que él mismo había inventado" (Arendt, 1998, p. 42).

\footnotetext{
${ }^{5}$ Estas condiciones son muy bien descritas por Hannah Arendt (1998) en la tercera parte de Origenes del totalitarismo.
} 
Cierto es que un nivel de ceguera tan extremo como el de Speer solo es posible si está antecedido por actos de engaño deliberado. Como en el caso del centinela medieval, el engañador frío y calculador, a fuerza de repetirse en su rol de engañador, termina por creerse su propia fabricación ${ }^{6}$, hasta negar, como vimos, aquello que es real, aquello que no es fabricado. Sin embargo, en "La mentira en política", también dice Arendt (1998, p. 44) lo siguiente: "El autoengaño presupone una distinción entre la verdad y la falsedad, entre el hecho y la fantasía y por ello un conflicto real entre el mundo real y el engañador autoengañado que desaparece en un mundo totalmente desasido de los hechos"'.

Hago propia la afirmación de Arendt, según la cual "el autoengaño" presupone una distinción entre la verdad y la falsedad, entre el hecho y la fantasía. Es justamente a esta distinción a la que responde, entre otras, la caracterización que intenté hacer del autoengaño, de la mano de la discusión filosófica. De dicha caracterización son constitutivos los términos "evasión" y "negación". Aquello que reclama la atención de un agente evasivo está de hecho allí para ser visto por él; está, justamente, reclamando su atención. Donde nada hay que reclame la atención de uno no hay tampoco nada qué evadir, no hay nada qué negar y, por lo tanto, no hay nada sobre lo cual engañarse. La cita de Arendt sugiere que la evasión que presupone una distinción entre lo que hay para ver y el hecho de que lo que hay para ver es evadido. En qué instancias de la mente tiene lugar esta distinción se encuentra, en gran medida, sujeto a la discusión; en qué instancias de la mente tiene lugar la consecuente negación está, también, sujeto a la discusión.

\footnotetext{
${ }^{6}$ En su libro Los hundidos y los salvados, dice Primo Levi lo siguiente: "Es cierto que hay quien miente conscientemente, falseando a sangre fría la irrefutable realidad, pero son más numerosos aquellos que levan anclas $[\ldots]$ y fabrican una realidad más cómoda $[. .$.$] .$ Es posible que al iniciar la situación, lo haga con plena conciencia de estar creando un guion enmendado, mendaz, restaurado [...]. Conforme se lo va repitiendo a los demás, pero también a sí mismo, las distinciones entre lo verdadero y lo falso pierden progresivamente sus contornos y el hombre termina por creer plenamente en el relato que ha hecho tantas veces y que sigue haciendo, limando y retocando acá y allá los detalles menos creíbles, incongruentes o incompatibles [...]. La mala fe inicial se ha convertido en buena fe. El paso silencioso de la mentira al autoengaño es útil: quien miente de buena fe miente mejor, recita mejor su papel, es creído con más facilidad por el juez, el historiador, el lector, la mujer y los hijos". (Levi, 2007, p. 24)

${ }^{7}$ El énfasis es mío.
} 
Más que tomar parte en estas discusiones quisiera destacar la manera como el autoengaño puede llegar a tornarse fácil. Esto ocurre, según creo, porque junto con el autoengañado la audiencia también cree algo que es falso. Los casos de autoengaño que son aislados, es decir, aquellos que tienen lugar ante una audiencia atenta a la evidencia no solamente se caracterizan por el modo como la audiencia llama la atención sobre el hecho de que el autoengañado evade la evidencia. Estos casos se caracterizan, también, por la forma como es notoria la impostura en el autoengañado. El "como sí", en contextos en los que los otros están atentos a la evidencia, si bien no adquiere un sentido psicológico distinto que en los casos en los que el autongaño es epidémico, sí se deja ver más nítidamente. Allí donde la audiencia no se confunde con el montaje escénico, allí donde ella está separada de quien "recita su papel" (Levi, 2007, p. 24) el autoengañado está, si se quiere, más expuesto y claramente le resulta más extraño a los demás. Allí donde, por el contrario, la audiencia sí se confunde con el montaje, es decir, en un mundo que, como dice Arendt (1998, p. 44), está totalmente "desasido de los hechos", la exposición y la extrañeza faltan. Y si estas dos cosas faltan, el "como sí" es, no solo compartido, sino también legitimado a través de la forma como es compartido.

Mi propósito en este texto ha sido solamente el de llamar la atención sobre el hecho de que el autoengaño puede llegar a ser más o menos notorio; pude llegar a ser más o menos fácil. Para hacer referencia esto no creo, sin embargo, que sea necesario determinar de qué forma sabe o cree el autoengañado aquello que niega saber o creer. Muy relacionado con esto, tampoco creo que sea necesario responder a la pregunta acerca de qué tanto alcanza el autoengañado a reconocer ante sí mismo las condiciones precisas en las que tienen lugar su impostura, su evasión y su negación. 


\section{Referencias}

Arendt, H. (1998). La mentira en política. Crisis de la república (pp. 11-55). (Trad. G. Solana). Madrid: Taurus.

Audi, R. (1988). Self-deception, Rationalization and the Reasons for Acting. B. McLaughlin \& A. Rorty (Eds.), Perspectives on Self-Deception (pp. 92-120). Berkeley: University of California Press.

Baron, M. (1988). What is Wrong with Self-Deception? B. McLaughlin \& A. Rorty (Eds.), Perspectives on Self-Deception (pp. 441-449). Berkeley: University of California Press.

ButLer, J. (1993). Fifteen Sermons. Virginia: Lincon-Rembrand Publishing.

Johnston, M. (1988). Self-deception and the Nature of Mind. B. McLaughlin \& A. Rorty (Eds.), Perspectives on Self-Deception (pp. 63-91). Berkeley: University of California Press.

Kershaw, I. (2007). Hitler. (Trad. J. Álvarez ). Barcelona: Península.

Levi, P. (2001). Los hundidos y los salvados. (Trad. P. Gómez). Barcelona: Muchnik.

Martin, M.W. (1986). Self-Deception and Morality. Kansas: University Press of Kansas.

Mele, A. (2009). Have I Unmasked Self-deception or am I Self-deceived? M. Clancy (Ed.), The Philosophy of Deception (pp. 260-275). Oxford: Oxford University Press.

Mele, A. (2001). Self-Deception Unmasked. Princeton: Princeton University Press.

RoRTy, A. (2009): User Friendly Self-Deception. M. Clancy (Ed.), The Philosophy of Deception (pp. 244-259). Oxford: Oxford University Press.

Rorty, A. (1988). The Deceptive Self. Liars, Layers, and Lairs". B. McLaughlin \& A. Rorty (Eds.), Perspectives on Self-Deception (pp. 11-28). Berkeley: University of California Press.

SpeER, A. (2001). Memorias. (Trad. R. Sala). Barcelona: Acantilado. 